\title{
Stronger Together! Meeting the Challenges of a Year Defined by a Pandemic
}

\section{Chuck Ingoglia, MSW}

Like most of us, I read A Tale of Two Cities in high school. The sweeping tale of intrigue, sacrifice, and epic romance was all but lost on an "ultra-sophisticated" 16-year-old like myself, but today, I find myself reflecting on these timeless words. They so perfectly sum up my feelings as I think back over the past year.

It was the best of times, it was the worst of times, it was the age of wisdom, it was the age of foolishness, it was the epoch of belief, it was the epoch of incredulity, it was the season of light, it was the season of darkness, it was the spring of hope, it was the winter of despair. ${ }^{1(\mathrm{p} .3)}$

I've been told that when Charles Dickens wrote them, he had no idea what he was going to write about; he didn't know what would happen next or how his tale would unfold. I sympathize and relate to Mr. Dickens' sense of bewilderment and uncertainty.

As I write this, the COVID-19 vaccine is being offered to everyone in most states. By the time you read this, hopefully, we'll have regained some sense of normalcy. But much of our tale is still unfolding and our course is far from certain.

The COVID-19 pandemic created obstacles that tested our resolve as a community and resilience as an organization. State of the Industry data released by the National Council found that $40 \%$ of mental health and substance use treatment organizations surveyed will not be able to keep their doors open past the end of the year without additional federal relief. ${ }^{2}$

But despite the challenges we faced, and continue to face, we forge ahead, never wavering from our commitment to increase access to high-quality, comprehensive care at all costs. We fought for financial relief. We helped expand telehealth. We brought critical legislation to the finish line. We were stronger together.

I cannot begin to describe the pride I feel to be part of this community. Or the many times I've been humbled by the courage I've observed. Together, we have met what seemed to be insurmountable challenges and we will be ready for whatever the future holds. We are that strong.

We advocated relentlessly for federal funding. The CARES Act provided much-needed financial lifelines through the Paycheck Protection Program and Provider Relief Funds in 2020. As the year came to a close, Congress passed a key National Council priority: the Crisis Stabilization and Community Reentry Act, as well as a \$2.4 trillion spending package that included \$1.4 trillion in appropriations for fiscal year 2021 and $\$ 900$ billion for COVID-19 relief.

Address correspondence to Chuck Ingoglia, MSW, National Council for Mental Wellbeing, Washington, DC, USA. Email: kmenendez@usf.edu.

Journal of Behavioral Health Services \& Research, 2021. 343-345. (C) 2021 National Council for Mental Wellbeing. DOI 10.1007/s11414-021-09762-4 
We successfully engaged Congress around Certified Community Behavioral Health Clinics (CCBHCs), resulting in a 3-year extension of the demonstration for the original eight states and the inclusion of two new states, Kentucky and Michigan, for the same period. We also helped secure the appropriation of an additional $\$ 850$ million in Substance Abuse and Mental Health Services Administration (SAMHSA) CCBHC expansion grants through the March 2020 CARES Act and December COVID-19 Relief package.

At the end of 2020, 229 CCBHCs were supported across 33 states. Today, there are 340 operating in 40 states, Washington, D.C., and Guam. Our "audacious aim" of 500 CCBHCs nationwide by 2025 will almost certainly be a reality by the end of 2021 . Then, we will set a new, even more audacious goal!

All the while, you've gone above and beyond to meet the needs of your staff, clients, and communities. You understood that to flourish, you needed to adapt.

At the onset of the COVID-19 lockdowns, when the pandemic disrupted the delivery of vital mental health and substance use treatment, especially to minorities and people with lower incomes who were disproportionately affected by pandemic-related job losses and social stress, your response was swift and sure. ${ }^{3}$ Instead of allowing the pandemic to derail you, you made major changes in the delivery of care to ensure that you could continue to provide treatment to those who rely on you. You embraced telehealth services with lightning speed to accommodate clients in safe, convenient online formats.

Those of you in the health-care continuum are the real heroes in this pandemic. And it's not over. As we look forward to the hope of a post-pandemic world, we must also prepare to meet the demand for mental health and substance use treatment services as we emerge from a period of unrelenting and unprecedented stress and hardship. As always, the $J B H S \& R$ offers insight and innovations that will serve us well as we continue to serve our communities.

Demand for youth mental health and substance use treatment services is already increasing; $63 \%$ of organizations are already seeing an increase in the demand for youth services. ${ }^{1}$ Two articles in this issue address this topic. Throughout the pandemic, young people have been exposed to unanticipated trauma as their fragile social framework was torn apart by separation from their peers, remote education, and missed milestones. In the months and years ahead, recognizing the toll of trauma on our youth and exploring ways to integrate trauma-informed care into primary care provision will become more critical (the Sala-Hamrick et al. paper in this issue). ${ }^{4}$ We will also need to explore new ways to implement parent/child-centric practices into all facets of care at community health clinics, like the cascading care model (the Brabson et al. paper in this issue). ${ }^{5}$

Depression is the leading cause of ill health and disability worldwide, and the COVID-19 pandemic has made all of us more vulnerable. It will become even more critical to employ effective tools to identify those at the greatest risk of depression and anxiety to ensure early treatment leading to recovery, like the Jung/Myers tool (the Rickles et al. paper in this issue). ${ }^{6}$ This is the kind of practical insight we have come to rely on from $J B H S \& R$.

While many will remember the COVID-19 pandemic because of what it took, I will remember it for what you gave, to your clients and your communities.

\section{References}

1. Dickens C. A Tale of Two Cities. London: James Nisbet \& Co. Limited, 1902.

2. Member Survey. National Council for Behavioral Health. Available online at https://www.thenationalcouncil.org/wp-content/uploads/ 2021/03/NCBH-Member-Survey-Feb-2021.pdf?daf=375ateTbd56. Accessed on January 1, 2021.

3. Kola L. Global Mental Health and COVID-19. The Lancet. Available online at https://www.thelancet.com/journals/lanpsy/article/ PIIS2215-0366(20)30235-2/fulltext. Accessed on January 1, 2021. 
4. Sala-Hamrick KJ, Isakson B, Del Campo De Gonzalez S, et al. Trauma-informed pediatric primary care: Facilitators and challenges to the implementation process. Journal of Behavioral Health Services \& Research. 2021;48(3). https://doi.org/10.1007/s11414-020-09741-1

5. Brabson L, Herschell AD, Snider MDH, et al. Understanding the effectiveness of The Cascading Model to implement parent-child interaction therapy. Journal of Behavioral Health Services \& Research. 2021;48(3). https://doi.org/10.1007/s11414-020-09732-2

6. Rickles NM, Olson AW, Tieger PD, et al. Use of the Jung/Myers Model of Personality Types to identify and engage with individuals at greatest risk of experiencing depression and anxiety. Journal of Behavioral Health Services \& Research. 2021;48(3). https://doi.org/ $10.1007 / \mathrm{s} 11414-020-09724-2$

Publisher's Note Springer Nature remains neutral with regard to jurisdictional claims in published maps and institutional affiliations. 